\title{
The wrong feet
}

\author{
Tony Whitehead
}

My first job in psychiatry was in a quiet backwater where little had changed since the hospital had opened in the 19th century. As a trainee I had no training but, nevertheless, did have responsibility for a number of long-stay wards.

I still remember one patient, a lady past middle age, who had come originally from Dudley in the West Midlands, but now wanted to go to Australia. Every day she told me that she must go to Australia but could not go because she had the wrong feet.

"I have got the wrong feet, doctor." She would say, "I must have the right feet before I can go to Australia."

The poor lady was diagnosed as suffering from schizophrenia as were most of the patients on the ward, but after many years in the hospital it was difficult to unravel the symptoms and signs of illness from the effects of institutionalisation.

Much later, when I was working in a small general hospital unit, a very different establishment, with no long-stay patients with the wrong feet, I saw Sir Alec Guinness in a television interview. He said that when he tried to get into a character he was playing he first had to get the feet right, meaning his stance, walk, etc.

I remembered my lady from the past and thought, perhaps, she had been correct. She had needed to get the right feet before she could be well and hopefully go to Australia.

Tony Whitehead, Consultant Psychiatrist, 2 Beacon Court, Greenways, Ovingdean, Brighton BN2 7AY

\section{NEW SERIES FROM GASKELL
Acute Psychosis, Schizophrenia and
Comorbid Disorders
Recent Topics from Advances in Psychiatric Treatment Volume 1}

This new series, Recent Topics from Advances in Psychiatric Treatment, will bring together popular articles from the Royal College of Psychiatrists' Continuing Professional Development Journal,Advances in Psychiatric Treatment. These have been updated to provide systematic, authoritative, and well referenced accounts of key clinical topics relating to modern therapeutic practice. Whilst primarily aimed at senior psychiatric trainees, many of the articles will be of interest to other mental health professionals.

The first volume covers the management of acutely disturbed in-patients, drug and psychosocial approaches to the treatment of schizophrenia, and the problems of comorbid substance misuse and homelessness. There are chapters on risk and childbirth, psychoses in the elderly, and the special problems of identifying and treating psychiatric disorders in those with learning disability. There is also practical advice on assessing fitness to be interviewed by the police, and on preparing medico-legal reports.

The book will be especially useful in conjunction with the College Seminars titles for those preparing for the College Membership Examinations.

\section{Autumn 1998, £15.00,152pp, ISBN 1901242161}

Available from good bookshops and from the Book Sales Department, Royal College of Psychiatrists, 17 Belgrave Square, London SW1X 8PG. Tel: +44 (0)171235 2351, ext. 146, Fax: +44 (0) 1712451231

The latest information on College publications is on the INTERNET at: http://www.rcpsych.ac.uk 